\title{
Semi-Lunar Variations of Endogenous Circa-Tidal Rhythms of Activity and Respiration in the Isopod Eurydice pulchra
}

\author{
M. H. Hastings \\ Department of Marine Biology, University of Liverpool, Port Erin, Isle of Man
}

\begin{abstract}
When collected from the shore and placed into infra-red beam actographs in constant darkness at $15^{\circ} \mathrm{C}$ in the laboratory, individual adult Eurydice pulchra Leach exhibit an endogenous circa-tidal rhythm of spontaneous swimming activity. Periodogram analysis of activity traces indicates a semi-lunar modulation in the rhythm's expression. It is most strongly expressed in isopods collected during spring tide periods. Groups of E. pulchra in moist sterilized sand were maintained in Gilson respirometers under constant darkness at $15{ }^{\circ} \mathrm{C}$; subsequent recordings of their respiratory rate demonstrated an endogenous circa-tidal rhythm of oxygen uptake, with peak rates at the time of expected high water This rhythm was expressed during spring tide, but not neap tide periods. Relationships of circa-tidal rhythms, their semi-lunar modulations and the semilunar emergence pattern of E. pulchra are discussed.
\end{abstract}

\section{INTRODUCTION}

Endogenous circa-tidal rhythms of activity have been recorded by several authors working on intertidal cirolanid isopods, including Eurydice pulchra (Jones and Naylor, 1970; Fish and Fish, 1972; Alheit and Naylor, 1976; Hastings and Naylor, 1980) and Excirolana chiltoni (Klapow, 1971). Similarly, the Mediterranean species Eurydice inermis, E. truncata and $E$. affinis have been shown to display a circadian rhythm of activity in constant conditions in the laboratory (Macquart-Moulin, 1976, 1977).

In the case of Eurydice pulchra spontaneous emergence from sediment in the laboratory occurs only at the time of spring tides; similarly Klapow (1971) demonstrated a semi-lunar modulation of endogenous rhythmicity in Excirolana chiltoni. However, Alheit and Naylor (1976) maintained of isopods collected from the surf in the laboratory without sand and demonstrated a persistent circa-tidal rhythm of swimming activity at both neaps and springs. This rhythm would only be expressed in the field after emergence from the sediment. Such emergence was suggested to be under the exogenous control of wave action and an endogenous circa-semi-lunar rhythm of expression (Fish and Fish, 1972; Alheit and Naylor, 1976). Field catches of $E$. pulchra in the surf plankton therefore varied with lunar phase and wave action (Jones and Naylor, 1970).
Spontaneous emergence and swimming of the population after highwater of spring tides would presumably facilitate ebb-transport down the beach and so prevent stranding above the water line. Such movements would explain the migration across the beach shown by E. pulchra through the semi-lunar cycle (Fish, 1970).

Semi-lunar rhythms have been described in several other marine arthropods, including Pseudaega punctata (Fincham, 1973), Excirolana chiltoni (Enright, 1972) and Tylos granulatus (Marsh and Branch, 1979), all isopods, the midge Clunio marinus (Neumann, 1976) and the uppershore amphipod Talitrus saltator (Williams, 1979).

The present paper attempts to characterize further the semi-lunar rhythmicity in Eurydice pulchra by analysis of the activity rhythm in the absence of sediment, and rhythms of respiratory rate which presumably reflect changes in the physiological state of the isopod.

\section{MATERIALS AND METHODS}

Adult individuals of Eurydice pulchra were collected from the upper shore at Derbyhaven, Isle of Man, by passing sand through a $1 \mathrm{~mm}$ aperture sieve. The day of collection was numbered relative to the semi-lunar cycle with the day of new or full moon being Day 1. 
The swimming activity of freshly-collected individuals in the absence of sediment was recorded in constant darkness at $15{ }^{\circ} \mathrm{C}$ by infra-red beam actographs coupled to a Rustrak event recorder and modified data logger (Atkinson et al., 1974). Hourly activity counts over $4 \mathrm{~d}$ were converted to percentages of maximum activity of each individual trace in order to make data comparable for the periodogram analysis performed by computer (Williams and Naylor, 1978). The strength of circa-tidal rhythmicity evident in the data was assessed in two ways. Firstly, the computer program indicated whether the periodogram indicated a statistically significant circa-tidal rhythm. Secondly, the magnitude was recorded of the deviation of the plot for a 12 or $13 \mathrm{~h}$ circa-tidal periodicity from the equivalent value on the regression line derived from a periodogram' of the randomized data. The greater this 'periodogram statistic', the stronger the rhythm. The units are arbitrary printing intervals used by the computer which are directly proportional to the S. D. values calculated by periodogram analysis.

The oxygen consumption rate of inactive isopods was measured using a Gilson respirometer. Each flask contained 10 individuals in about $3 \mathrm{~mm}$ deep moist sand, which had been sterilized by washing in acid and was then rinsed several times with distilled water to remove any soluble organic residue or nutrients. Bacterial growth would therefore have been minimal for the duration of the experiment. The isopods were unable to express their endogenous swimming rhythm and so changes in respiratory rate were independent of such activity fluctuations. The flasks remained unshaken to avoid possible entrainment effects (Jones and Naylor, 1970). Each experiment used 3 replicate flasks with a fourth control without isopods to ensure that the sand did not contain respiring microorganisms. The experiments commenced after over-night acclimation of the isopods and were run at $15{ }^{\circ} \mathrm{C}$ in constant darkness with measurements every $30 \mathrm{~min}$ for $24 \mathrm{~h}$. Metabolic rate was calculated as $\mu$ l of oxygen consumed $\mathrm{mg}^{-1}$ dry weight $\mathrm{h}^{-1}$. To make the three replicates comparable, this was converted to percentage of maximum rate for each flask. A mean value was then obtained from the three replicate percentage rates. One flask was recorded for $60 \mathrm{~h}$ to demonstrate the persistence of the endogenous rhythm.

\section{RESULTS}

\section{Activity Traces}

Figure 1 shows the hourly activity values over several days for a single Eurydice pulchra collected during a spring tide. The spontaneous swimming activity

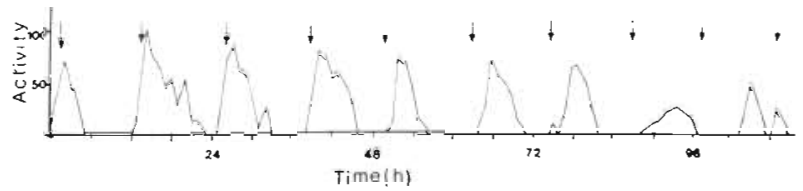

Fig. 1. Eurydice pulchra. Hourly swimming activity of a single individual recorded in an electronic infra-red beam actograph without sand and in constant conditions after collection from the field during a spring tide. Arrows indicate time of expected high water

demonstrates a very precise endogenous circa-tidal rhythmicity with peak activity occurring at the expected time of high-water or early ebb, and minimal values around expected low water. The rhythm free ran for approximately 8 tidal cycles, drifting slightly later each day.

Figure 2 gives computer-plotted periodograms performed upon 4 individual Eurydice pulchra traces, 2 from spring $(a, b)$ and 2 from neap ( $c, d)$ tidal periods.

Figure $2 \mathrm{a}$ and $\mathrm{b}$ show a strong, significant circa-tidal rhythm of 12 and $13 \mathrm{~h}$ periodicity, respectively, with very large periodogram statistics. Of the neap traces, 2 c shows no significant circa-tidal rhythm while the
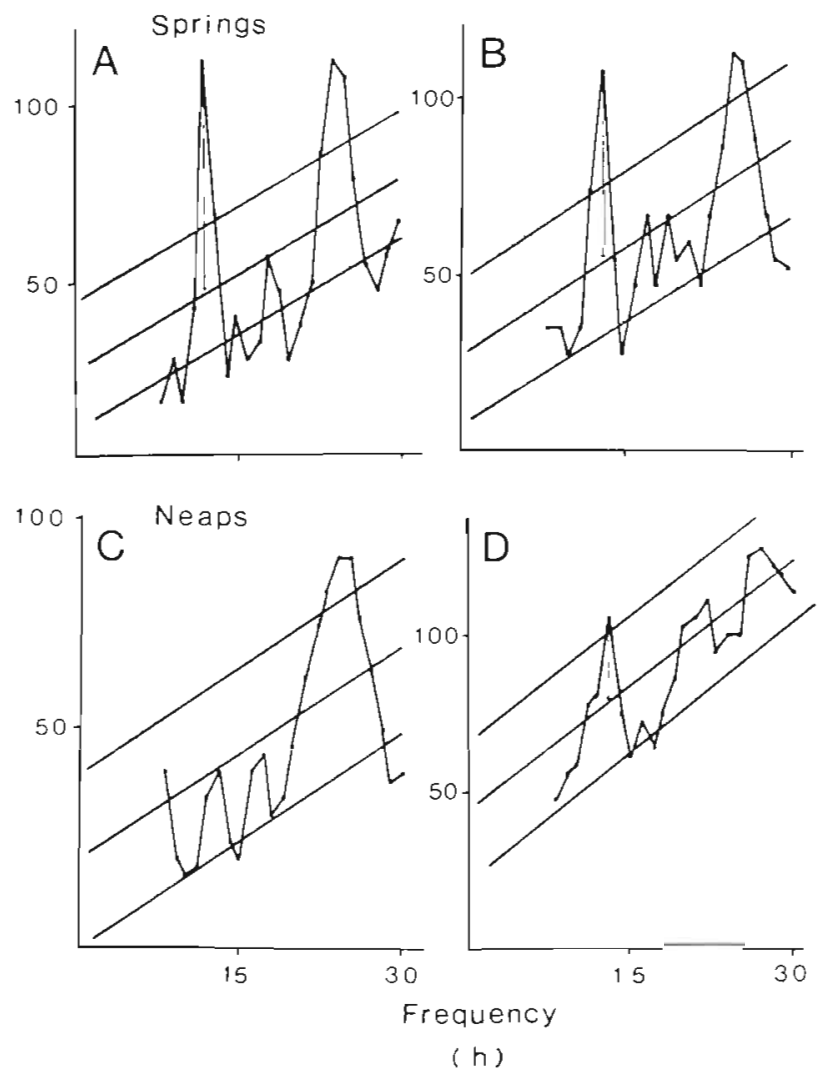

Fig. 2. Eurydice pulchra. Computer-plotted periodogram treatments of 4 individual activity traces; individuals $A$ and $B$ collected on spring, C and D on neap tides. Vertical lines indicate periodogram statistic measurement; deviation of the observed plot from an expected random value 
$13 \mathrm{~h}$ rhythm in $2 \mathrm{~d}$ is significant, i. e. the deviation is outside the S. D. of the randomized data, but is very weak with a small periodogram statistic. Three periodograms (A, B, C) show a significant rhythm with a frequency of 23 to $25 \mathrm{~h}$. This may represent a double period of the circa-tidal, i. e. 12-13 h rhythm (especially in $A$ and $B$ ) as well as any effect of circadian periodicity present in the data.

Figure 3 gives a plot of the periodogram statistic against the day of collection of 62 individual traces. The largest and consistently significant values are given by individuals collected just after new and full moon on Days 1 to 4 . The smallest values are concentrated about Days 8 to 11 , the neap tide period, where 15 out of 25 individuals recorded failed to show a statistically significant circa-tidal rhythm. The value of the periodogram statistic increases towards the next spring tide period with values approaching those in the early part of the cycle, and all of the isopods display a significant rhythm by Day 15 . The tendency for the periodogram value to increase with distance from the minimal values of Day 8 was tested by Kendall's Ranked Scores (Meddis, 1975). Day 8 was ranked 0 , Days 7 and 9 as 1, Days 6 and 10 as 2, etc. A highly significant result $(\mathrm{P}<0.001)$ was obtained ( $\mathrm{s}=724, \mathrm{n}$ $=62, \mathrm{z}=4.29$ ) indicating that there is a very strong trend in the data for an increased value of periodogram statistic towards spring tides with a minimum at neaps. It can be concluded that the spontaneous circa-tidal activity rhythm of Eurydice pulchra therefore undergoes a semi-lunar modulation. It is strongly expressed in all individuals during spring tides, but only a minority of isopods at neap tides are rhythmic, and even then the expression of their activity rhythm is very weak.

\section{Oxygen Consumption}

Figure 4 is a plot of respiratory rate for 10 Eurydice pulchra over $60 \mathrm{~h}$ after collection during a spring-tide period. A strong circa-tidal rhythm is evident with peaks of increased respiration (1.0-1.2 $\mu \mathrm{l} \mathrm{O}_{2} \mathrm{mg}^{-1} \mathrm{~h}^{-1}$ ) at the times of expected high water and lowest rates $\left(0.7-0.8 \mu \mathrm{l} \mathrm{O}_{2} \mathrm{mg}^{-1} \mathrm{~h}^{-1}\right)$ at expected low water. The overall change represented an increase of about $50 \%$ over the basal rate. The $12 \mathrm{~h}$ form-estimate of the trace (Fig. 5) indicates the overall pattern of the rhythm.

Figures 6 and 7 are 24 h plots of the metabolic rate of individuals collected throughout the semi-lunar cycle, each plot being the mean of 3 replicates with values expressed as percentages of the maximum value in each experiment. The overall mean value for the $24 \mathrm{~h}$ is plotted in form of a straight line as a baseline from which to assess the temporal variations. None of the

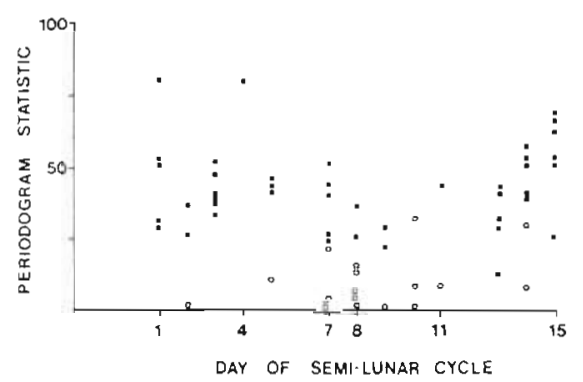

Fig. 3. Eurydice pulchra. Plot of periodogram statistic calculated for activity traces of individuals collected on different days of the semi-lunar cycle and recorded under constant darkness and temperature. Filled squares: significant circatidal rhythm in trace; open squares: statistically non-significant circa-tidal rhythm in trace

plotted values reach 100 percent because they are mean values derived from 3 separate replicates which did not all approach 100 percent simultaneously.

Isopods collected on Day 2 showed a very strong endogenous rhythm similar to that in Figure 5, with peak rates of metabolism at the times of expected high water and minima at low tide. This circa-tidal rhythm is present in isopods collected on Day 4, but is absent from individuals collected during neap tides on Days 7 and 9 . Here the respiratory rate fluctuates erratically around the mean value with an overall range smaller than that seen during springs.

Isopods collected on Day 12 give a suggestion of the rhythm with small peaks around high water and the rhythm is fully re-established by Day 15 when the semi-lunar cycle has returned to spring tides. The overall change in the rhythm is around $50 \%$ of the basal rate, as suggested earlier in Figure 5.

These data demonstrate that the endogenous circatidal rhythm of oxygen consumption is subject to a semi-lunar modulation such that it is expressed during spring, but not neap, tides.

\section{DISCUSSION}

The present experiments confirm the strong circatidal rhythm of spontaneous swimming in Eurydice pulchra when maintained in the laboratory without

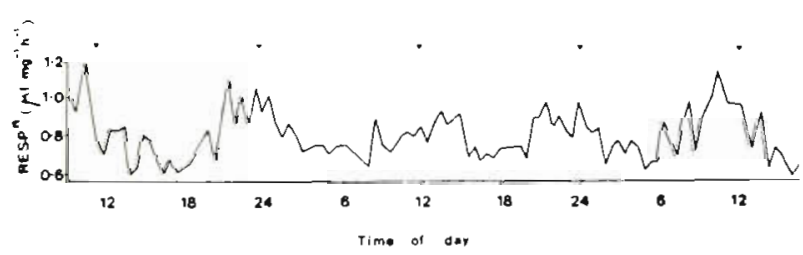

Fig. 4. Eurydice pulchra. Hourly respiratory rate of 10 individuals maintained in moist sand in Gilson respirometer for 5 tidal cycles under constant conditions. Arrows indicate time of expected high water 


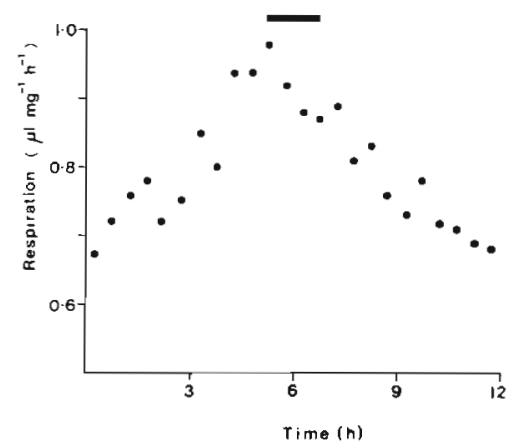

Fig. 5. $12 \mathrm{~h}$ form estimate of data in Figure 4. Bar indicates position of successive expected high waters

sand, as previously described by Jones and Naylor (1970) and Alheit and Naylor (1976). This rhythm has been shown, after extensive recording throughout the spring-neap cycle, to undergo a semi-lunar modulation such that it is expressed strongly by the whole population during spring tides, but only weakly and by a minority of the population during and just after neaps.

Alheit and Naylor (1976) presented activity traces of isopods collected from the surf plankton during both

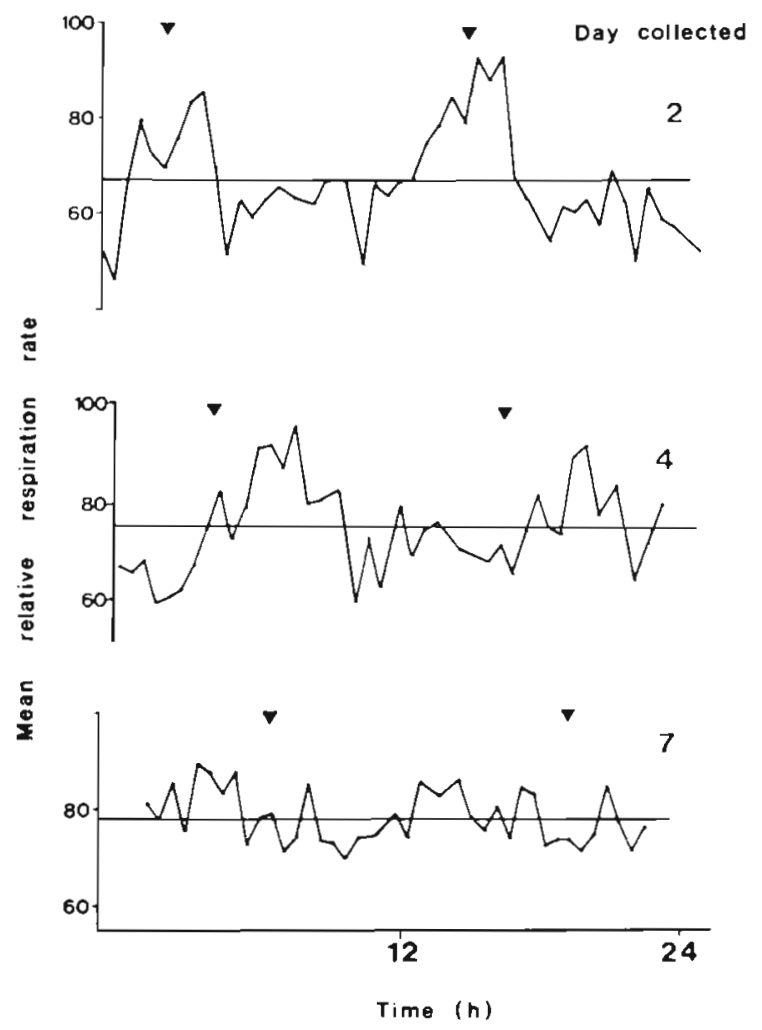

Fig. 6. Eurydice pulchra. Mean relative respiratory rate of groups of 30 individuals maintained in Gilson respirometer under constant conditions after collection from the field on different days of semi-lunar cycle and over-night acclimation. Lines indicate overall $24 \mathrm{~h}$ mean rate, arrows time of expected high water

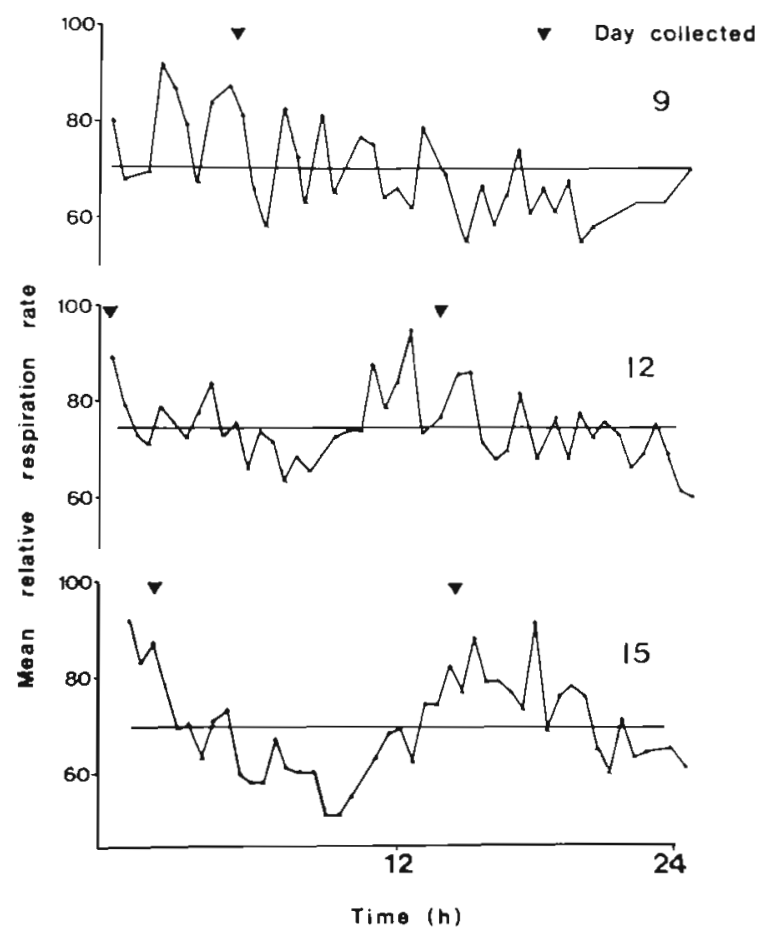

Fig. 7. Eurydice pulchra. Mean relative respiratory rate of groups of 30 individuals maintained in Gilson respirometer under constant conditions after collection from the field on different day of semi-lunar cycle and over-night acclimation. Lines indicate overall $24 \mathrm{~h}$ mean rate, arrows time of expected high water

spring and neap tides, and demonstrated the presence of a circa-tidal swimming rhythm in the absence of sand in both cases, although the overall activity level was much reduced at neaps. In the light of present results, it seems likely that recordings of more isopods collected from the sediment rather than from surf would have shown that the rhythmic individuals were in fact in a minority during neap, but not spring, tides. The suggestion of a semi-lunar modulation of the spontaneous emergence rhythm made for Eurydice pulchra by Fish and Fish (1972) and Alheit and Naylor (1976) could also be applied to the expression, on a population basis, of the circa-tıdal swimming rhythm.

Jones (1970) recorded the respiratory rate of Eurydice pulchra in inactive and actively swimming indi-

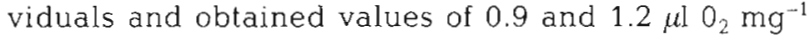
wet weight $h^{-1}$, respectively. The present rates quoted on a dry weight basis are therefore much higher, but they compare well with values (given as $\mu \mathrm{O}_{2} \mathrm{mg}^{-1}$ dry weight $\mathrm{h}^{-1}$ ) for respectively inactive and active Tylos granulatus of 0.5 and 1.5-2.0 (Marsh and Branch, 1979), for Pontoporeia affinis of 0.4 and 1.3 (Cederwall, 1979) and for Gammarus oceanicus of 0.61 and 1.5 (Halcrow and Boyd, 1967). These data yield an average 3 -fold increase in respiration with activity, compared 
to the $50 \%$ increase over basal rate in the rhythmic $E$. pulchra at expected high tide. This is presumably a result of the suppression of overt activity in the isopods.

The endogenous rhythm of respiration was noted by Jones (1968) with inactive animals in sand showing a peak in metabolic rate coincident with expected high water, and minima at expected low water. Circa-tidal respiratory rhythms are also recorded for the isopods Tylos granulatus (Marsh and Branch, 1979) and Naesa bidentata (Wieser, 1962). However, these animals were free to move in their chambers and so the rhythm could not be said to be independent of any activity changes. A similar situation exists with recordings of Emerita asiatica, the mole crab, (Chandrashekaran, 1965) and species of $U_{C a}$ (Brown et al., 1954). In contrast, a circatidal rhythm of respiration independent of activity was demonstrated in Carcinus maenas by Arudpragasam and Naylor (1964) using tethered individuals.

The semi-lunar modulation of the endogenous respiratory rhythm described here is new and has important implications when considering the nature of the semi-lunar emergence rhythm reported for Eurydice pulchra (Fish and Fish, 1972; Alheit and Naylor, 1976; Hastings and Naylor, 1980). The present paper describes two parallel rhythms; both are circa-tidal with peaks around high water, both are persistent over several days and both are subject to a semi-lunar modulation with strongest expression during spring tides. These properties are shared with the spontaneous emergence rhythm described by Fish and Fish (1972), Alheit and Naylor (1976) and Hastings and Naylor (1980), and it would seem most economical to suggest that all three are manifestations of the same phenomenon, namely a single circa-tidal oscillation which pervades the entire physiology of E. pulchra.

The respiratory rate may be assumed to be a reflection of changing states of excitability of the test animal. In the absence of sediment, the high level of excitability around expected high water results in spontaneous swimming activity, facilitated by the increased metabolic rate. In the presence of sediment, emergence would be inhibited by any thigmokinetic response and so overt swimming would occur only when the level of excitation exceeded the threshold value of this response. This would only occur at expected high tide and during early ebb. As the level of excitability began to wane, the animal would return to the sediment before expected low water. The lower metabolic rate would enhance energy conservation.

The result of the semi-lunar modulation of the rhythm would be that during neaps the poorly rhythmic or arhythmic isopods would rarely show the peak values of excitability (seen as increased respiration) that would lead to spontaneous emergence. Conse- quently, such emergence is rarely seen in isopods collected during neap tides.

The relative importance in the field of the spontaneous emergence rhythm would vary with locality and history of the population. Those studied by Jones and Naylor (1970) inhabited a high-energy beach and the numbers swimming were related to wave action. Derbyhaven beach is more sheltered, and direct physical displacement of Eurydice pulchra from the sediment by turbulence is unlikely. Here spontaneous emergence would be more important and may be expected to be expressed more strongly by the population. In both cases, the cessation of swimming activity due to the rhythm's influence would enable both populations to return to the sand below the next HWM yet without being carried off-shore by the ebb tide.

The entrainment mechanism of the circa-semi-lunar rhythm has still to be assessed. Jones and Naylor (1970) demonstrated the entraining. effect of turbulence on the circa-tidal swimming rhythm in Eurydice pulchra, and the same zeitgeber has proved to be effective in entraining activity in Excirolana chiltoni (Enright, 1965; Klapow, 1972). The inter-action of such a circa-tidal stimulus with the solar day has been proposed as a possible basis for semi-lunar modulation of activity (Bünning and Müller, 1961; Barnwell, 1968) and certainly Hastings and Naylor (1980) demonstrated an endogenous diurnal modulation in the spontaneous emergence of groups of adult E. pulchra in the laboratory when supplied with sediment. In the present experiments, individual isopods were maintained in actographs without sediment, which is a different approach from that of Hastings and Naylor (1980). A circadian periodicity was less evident in the present results, although significant rhythms with a period of 23 to $25 \mathrm{~h}$ were seen in various periodogram analyses. However, it is difficult to decide how much these rhythms were based upon a double period of the basic 12 or $13 \mathrm{~h}$ circa-tidal oscillation and how much they reflected a true 24 h independent circadian rhythm. The origin of the semi-lunar modulation of the circatidal rhythm therefore remains unexplained.

Acknowledgements. The author is very grateful to $\mathrm{Mr}$. H. Bailey for the construction and patient maintenance of the electronic recording apparatus and to Professor E. Naylor for helpful discussion. The work was supported by N. E. R. C.

\section{LITERATURE CITED}

Alheit, J., Naylor, E. (1976). Behavioural basis of intertidal zonation of Eurydice pulchra Leach. J. exp. mar. Biol. Ecol. 23: 135-144

Arudpragasam, K. D., Naylor, E. (1964). Gill ventilation volumes, oxygen consumption and respiratory rhythms in Carcinus maenas (L.). J. exp. Biol. 41: 309-321 
Atkinson, R. J. A., Bailey, H., Naylor, E. (1974). Some laboratory methods for recording and displaying temporal patterns of locomotor acitvity in marine animals. Mar. Behav. Physiol. 3: 59-70

Barnwell, F. H. (1968). The role of rhythmic systems in the adapation of fiddler crabs to the intertidal zone. Am. Zool. 8: 569-583

Brown, F. A., Jr., Bennett, M. F., Webb, H. M. (1954). Persistent daily and tidal rhythms of oxygen consumption in fiddler crabs. J. cell comp. Physiol. 44: 477-505

Bünning, E., Muller, D. (1961). Wie messen Organismen lunare Zyklen? Z. Naturforsch. 16 B: 391-395

Cederwall, H. (1979). Diumal oxygen consumption and activity in 2 Pontoporeia (Amphipoda: Crustacea) species. In: Naylor, E., Hartnoll, R. G. (eds) XIII European Marine Biology Symposium, Cyclic Phenomena in Marine Plants and Animals. Pergamon, Oxford. pp. 309-316

Chandraschekaran, M. K. (1965). Persistent tidal and diurnal rhythms of locomotor activity and oxygen consumption in Emerita asiatia (M-Edw). Z. vergl. Physiol. 50: 137-150

Enright, J. T (1965). Entrainment of a tidal rhythm. Science, N. Y 147: 864-867

Enright, J. T. (1972). A virtuoso isopod. J. comp. Physiol. 77 141-162

Fincham, A. A. (1973). Rhythmic swimming behaviour in the New Zealand sand beach isopod Pseudaega punctata. J. exp. mar Biol. Ecol. 11: 229-237

Fish, S. (1970). The biology of Eurydice pulchra (Crustacea: Isopoda). J. mar. Biol. Ass. U. K. 50: 753-768

Fish, J. D., Fish, S. (1972). The swimming rhythm of Eurydice pulchra and a possible explanation of intertidal migration. J. exp. mar. Biol. Ecol. 8: 195-200

Halcrow, K., Boyd, C. M. (1967). The oxygen consumption and swimming activity of the amphipod Gammarus oceanicus at different tempertures. Comp. Biochem. Physiol. 23: 233-242

Hastings, M. H., Naylor, E. (1980). The ontogeny of an endogenous rhythm in Eurydice pulchra. J. exp. mar. Biol. Ecol. 46: 137-145
Jones, D. A. (1968). Some aspects of the biology of the isopod genus Eurydice. Ph. D. thesis, University of Wales

Jones, D. A. (1970). Factors affecting the distribution of the intertidal isopods Eurydice pulchra Leach and E. affinis Hansen in Britain. J. anim. Ecol. 39: 455-472

Jones, D. A., Naylor, E. (1970). The swimming rhythm of Eurydice pulchra. J exp. mar. Biol. Ecol. 4: 188-199

Klapow, L. A. (1971). The ecology and behaviour of a sandbeach isopod, Excirolana chiltoni: distribution, abundance and temporal patterns in molting, reproduction and swimming activity. Ph. D thesis, University of California

Macquart-Moulin, C. (1976). Persistent activity rhythms of Peracarida of nocturnal plankton of the Mediterranean. Mar Behav. Physiol. 4: 1-15

Macquart-Moulin, C. (1977). Le contrôle de l'emergence et des nages nocturnes chez les peracarides des plages de Méditerranée. Eurydice affinis, Gastrosaccus mediterraneus e G. spinifer. J. exp. mar. Biol. Ecol. 27: 61-81

Marsh, B. A., Branch, G. M. (1979). Circadian and circatidal rhythms of oxygen consumption in the sandy-beach isopod Tylos granulatus Krauss. J. exp. Mar. Biol. Ecol. 37: $77-89$

Meddis, R. (1975). Statistical handbook for non-statisticians, McGraw Hill, England

Neumann, D. (1976). Adaptations of chironomids to intertidal environments. A. Rev. Ent. 21: 387-414

Wieser, W (1962). Adaptations of two intertidal isopods. I. Respiration and feeding in Naesa bidentata Adams (Sphaeromatidae). J. mar. Biol. Ass. U. K. 42: 665-682

Williams, J. A. (1979). A semi-lunar rhythm of locomotor activity and moult synchrony in the sand beach amphipod Talitrus saltator In: Naylor, E., Hartnoll, R. G. (eds) XIII European Marine Biology Symposium, Cyclic Phenomena in Marine Plants and Animals. Pergamon, Oxford, pp. $407-414$

Williams, J. A. Naylor, E. (1978). A procedure for the assessment of significance of rhythmicity in time-series data. Int J. Chronobial. 5: 435-444 